\title{
The COVID-19 Pandemic and Telemedicine Adoption: Challenges and Opportunities
}

\author{
Mohammad Hamsal ${ }^{1}$, Mohammad Ichsan ${ }^{2}$ \\ $\left\{\right.$ mhamsal@binus.edu'1 ${ }^{1}$ d3919@binus.ac.id $\left.{ }^{2}\right\}$ \\ Management Department, BINUS Business School Doctor of Research in Management, \\ Bina Nusantara University, Jakarta, Indonesia $11480^{1}$, \\ Management Department, BINUS Business School Undergraduate Program, \\ Bina Nusantara University, Jakarta, Indonesia $11480^{2}$
}

\begin{abstract}
The adoption of telemedicine services globally is becoming more intensive during the COVID-19 pandemic. Such phenomenon exists also in Indonesia but with less magnitude, it is adopted mostly due to enforcement from the government's appeal for social distancing. Despite the importance of telemedicines in Indonesia, the challenges of its adoption are inevitable such as regulation and infrastructure readiness. This paper explores some challenges and opportunities of telemedicine adoption in Indonesia during the pandemic. The data from 60 hospitals are collected through e-questionnaire and further analysis is done using statistical tools. The study found that around half of the respondents have adopted the telemedicine where most of them are located in highly populated island and the rest have put short, medium and long term plan to apply it. The hospitals are in favour to keep on extending the adoption of telemedicine despite the challenges in applying it much wider geographical location.
\end{abstract}

Keywords: COVID-19, disruptive innovation, health technologies, pandemic, social distancing, telehealth, telemedicine

\section{Introduction}

There is a growing interest to conduct research in area of telehealth in conjuction with the COVID-19. The impact of COVID-19 on business and management is continuously attracting many researchers, who are bringing new perspectives on the research [1]. The COVID-19 pandemic is again reminding us of the importance of using telemedicine to deliver care, especially as means of reducing the risk of crosscontamination caused by close contact [2]

The currently ongoing COVID-19 pandemic has been shaking the global economy and corporate entities. How consumers and business institutions deal with the pandemic will influence customers, employees, and the economy at large [3]. It was started on December 2019 in Wuhan province in China before it infected every part of the world [4],[5],[6]. The spread of coronavirus pandemic is unprecedented and has reached 199 countries around the world and has affected over 556,141 people, testing positive for this new virus [7]. Estimating the virus' effect on the global economy is very challenging. The SARS outbreak is believed to have cost of about US $\$ 40$ billion while the economist who made that calculation predicts COVID-19 could cost three or four times as much [8]. Without exception, Indonesia reported its first two COVID-19 cases on March 2, 2020 [9]. As of July 25, 2020; the cases have increased to 97,286 people in 34 provinces [10]. The COVID-19 pandemic hits Indonesia's economy almost in all sectors as evidenced by the fall of Indonesia Rupiah currency and Indonesia Composite Index. The Indonesian 
government policy to apply social distancing and encourage working from home has caused business organizations to rely on online platforms and digital activities to survive [11].

One of the concerns raised during this disruption is healthcare institutions including hospitals that play a crucial role in this pandemic situation. The fight against COVID-19 has the potential to accelerate a new business and operating model for organizing and managing health system globally [1]. Hence, it is worth to analyze and discuss how hospitals face crises and disasters and achieve business sustainability during and post-pandemic situation. From hospitals' perspective it will involve opportunities and threats.

The quick spread of COVID-19 pandemic in the last few months has created turbulence in the business environment and threatens hospitals' business continuity. The situation has increased their awareness as they are living in a volatile and uncertain business environment. Hospitals, therefore, have to cultivate several practical strategies and mechanisms to be resilient to turbulences and seize opportunities emerging from this pandemic crisis. The global health system has been severly affected by coronavirus pandemic. The mortality level, number of cases and the deterioration of health system have been increased due to shortages of supplies, quality of public health infrastructures and lack of coordination among related stakeholders [12].

The crisis of COVID-19 has immediately lead to the digital-based solutions to minimize the impact of the pandemic [1]. In Indonesian context, the solution has been used as an approach that allows the patients to be remotely examined and easily accessible without harming the clinicians during the COVID-19 outbreaks to use telemedicine. Hollander and Carr [13]argued that major challenges of telemedicine services during this pandemic are testing coordination, expansion of testing sites, mitigating risk exposure while performing test using dedicated infrastructures by performing telemedicine system. However this solution will not replace all medical cares [14].

This study has the objective to investigate the adoption of telemedicine services in Indonesia during the COVID-19 pandemic, including its challenges and opportunities.

\section{Literature Review}

The theory of disruptive innovation has proved as a powerful concept about innovationdriven growth which originating in low-end and new market footholds [15]. Deloitte [16] reported that exponential innovation has been emerging in several industries such as transportation (the raise of hybrid car), entertainment (digital music), telecommunication (smartphone) and also healthcare (robots in the operating room). It means that the growth of this innovation can be expected to be more enhanced in the future.

In the last decade, unlike other industries, healthcare had been widely resistant to disruptive innovation and getting costlier in contrast to media, telecom, retail, and finance industries which had become much more affordable and accessible [17],[18]. In health care industry, advanced technologies such as robotics, sensors, artificial intelligence, genomics, data analytics, nanotechnology, and virtual reality are inevitable in the future [14]. Hence, these innovations may change the operating models of hospital in the coming years. The disruptive health technologies such as on-demand telemedicine will undertake efforts to attract an early majority of adopters [19]. This kind of disruption offers solution in addressing the rising costs and uneven quality of healthcare by enabling technology, implementing innovative business model, and create value network [17]. According to Smith et al. [20], telemedicine is disruptive, complex, and a lot of new methods to be learned by the clinicians, however they accept this solution to be effective, safe, and normal.

Health organizations will progressively use on-demand telemedicine to fulfill the rising patient demand for services that are convenient, accessible, and affordable [19]. It offers a new way to support long-distance clinical care, education, and health care, from first response to recovery with affordable cost and extensive coverage [21]. The key to stimulating the industry 
disruption is improving the causal mechanism, that is how to assist individuals to be healthy. Some barriers such as reimbursement issue, inconvenience usage especially for patients and clinicians in rural areas, and high investment are considered by health care providers [22]. While, Ohanessian et al [23] argue that telemedicine requires several conditions such as national regulations and funding, strategy, standard, guidelines, communication infrastructures, and database mechanism.

\section{Methodology and Data Analysis}

The design of this study is empirical and quantitative. The unit of analysis is health care service provider such as hospital and clinic. The proposed sampling method for this research is non-probability sampling namely purposive sampling. The targeted respondents are business owners, member of the board of directors, and general/senior managers of hospitals and clinics. Due to pandemic outbreaks that encourage social distancing, the data are collected through electronic survey using a structured quesionnaires with 5 points Likert scale (from 1=" strongly disagree" to $5=$ " strongly agree") that is distributed during a webinar, through emails, LinkedIn and closed networking tools such Whatsapp. To check the research tools' validity and reliability, a pilot test has been performed. The data is analyzed using descriptive analysis with SPSS and MS Excel as analysis tools.

\section{Research Result and Discussion}

From the distributed questionnaires and after reviewing the result, the feedback from 60 respondents are collected and further analysed. Based on the responses, most hospitals and clinics are class $\mathrm{C}$ followed by class B, where both are mostly private owned. Then, 26 (43\%) respondents are hospital/clinic class $\mathrm{C}$ followed by 19 (32\%) class B hospitals/clinics. There are $34(57 \%)$ hospitals are owned by corporation, while the rest of ownership are evenly distributed to government, local government, foundation and individuals. Based on location, 24 hospitals $(40 \%)$ are located in Banten province where they are dominated by class $\mathrm{C}$ hospitals and followed by DKI Jakarta province where 13 hospitals (22\%) are located. The rest are mainly in Java island (6 hospitals) and Sumatera island ( 8 hospitals).

Telemedicines are adopted by 29 out of 60 hospitals, where 15 of them (51\%) are class B hospital and located in provinces in Java island such Banten, DKI Jakarta and West Java. Furthremore, there are 12 class $\mathrm{C}$ which also mainly located in Banten. Meanwhile, there are 31 hospitals $(52 \%)$ whch are planing to implement it and they are categorized into short-term (3-6 months), medium-term (6-12 months) and long-term (more than 12 months). In the United States, $57 \%$ of health care providers view telehealth/telemedicine more favorably than they dis before COVID-19 and 76\% of patients are interested in using telehealth/telemedicine in the future [24]. There are 13 hospitals (42\%) which have short-term plan to adopt telemedicine. They are mainly in class B hospitals and located in Java island. Furthermore, the adoption of telemedicines in medium-term is considered by 8 hospitals $(26 \%)$ which mainly also in Java. The long-term plan for telemedicine adoption is taken into consideration by 10 hospitals (32\%) spreading in relatively same portion in Java and Sumatera island. The results support the proposition of Verma \& Gustafsson [1] who argue that the COVID-19 crisis requires short-, 
medium-, and long-term plans to realign a solid initiative for robust and sustainable business strategies across every sector.

Relating the survey of respondents due to pandemic awareness with the adoption strategy of the telemedicine is becoming imperative as shown in Figure 1. From the total respondents, 54 of them believe that there is an urgent needs of public health during COVID-19 pandemic, meanwhile 47 respondents agreed that this pandemic is becoming a threat to public health and 28 respondents think that they only have limited information. Last but not least, there are 44 respondents who believe that public health has become uncertain during this pandemic.
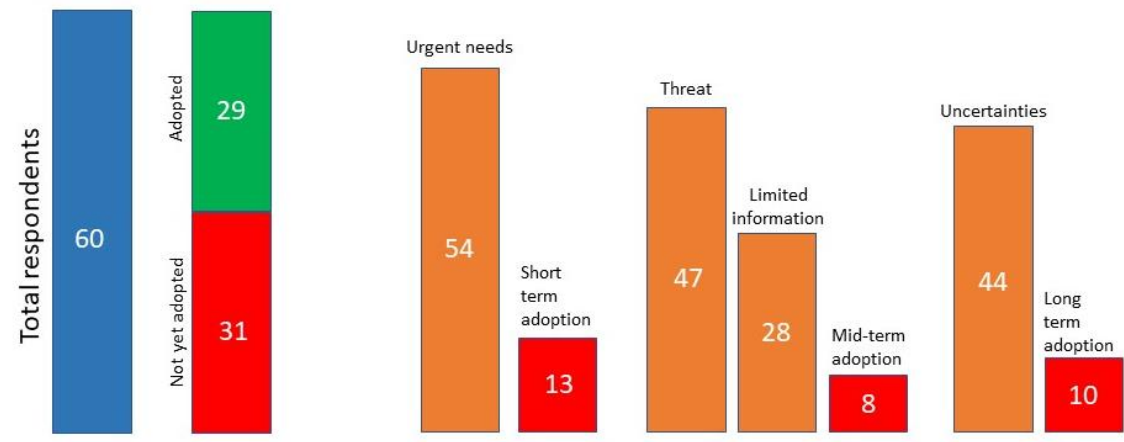

Fig. 1. Telemedicine - Pandemic awareness and telemedicine adoption strategy

During the COVID-19 pandemic, telemedicine is one of the main reasons why it is adopted, where social distancing measures has raising in line with the growth of the pandemic victims as shown Figure 2. The concern during pandemic can be fulfilled by applying telemedicine as most of the reasons in telemedicine application is due to government requirement to have minimized contact in hospitals ( 42 responses) and followed by initiatives by hospitals to add values to their services as well as due to hospital's policy.

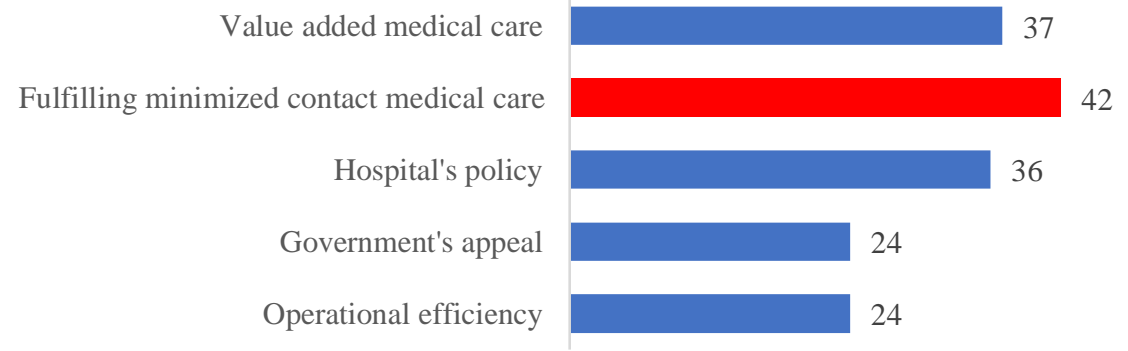

Fig. 2. Reasons to adopt telemedicine

The adoption of telemedicine in Indonesia has gained momentum during this pandemic especially when the government and Indonesian Medical Doctors Association have open the 
access to the physicians in limited condition to perform telemedicines as preventive measures to those who needs healthcare assistant [25],[26]. From the data it can be seen that almost half of the hospitals have adopted telemedicines and the rest are planning for adoption as short, medium and long term plan. Despite the wide opportunities, the adoption of telemedicines have challenges, especially due to limited technology infrastructure readiness and supportive regulations. The technology infrastructure readiness can be seen that most of the hospitals are located in Java island where the technology infrastructure readiness such internet and fiber optics are relatively high compare to the other islands. However, the regulation is one of the key challenges that is not considered as one of major reasons in adopting telemedicine as shown in Figure 2.

\section{Conclusion}

Nothing is more critical than our health. Telehealth does have an important role in crisis responses. Advantages of telehealth include the ability to rapidly deploy large numbers of providers, facilitate triage so that front-line providers are not overwhelmed with new presentations, supply clinical services when local hospitals or clinics are damaged or unable to meet demand, and decrease the risk of communicable diseases which are transmitted by personto-person contact [20].

The telemedicine adoption in Indonesia has had momentum during the COVID-19 crisis. Many governments have relaxed all restrictive regulations for telemedicine adoption [14]. Consistent with this Indonesian government and Indonesian Medical Doctors Association (IDI) have relaxed the regulation by opening access to the physicians in limited condition to perform telemedicines as preventive measures to those who needs healthcare assistant [25],[26]. This can be seen that almost half of the hospitals have adopted telemedicines and the rest are planning to adopt in short-, medium- and long-term plan. Despite the wide opportunities, the adoption of telemedicines has challenges, especially due to limited technology infrastructure readiness, patient experience and outcomes, physician capabilities and alignment, and supportive regulations.

\section{Limitations and Suggestions for Further Research}

Interpretation of the findings of this research is subject to some limitations. First, this study is based on a cross-sectional nature and might fail to capture the overall picture of challenges and opportunities in adopting telemedicine. As this study has used small sized samples that leads to unoptimized result, it is suggested to enlarge the sample size as well as applying to other related healthcare sectors such as pharmaceutical and medical devices. Furthermore, it is also proposed to empirically analyze the relationships between telemedicine and other related variables.

\section{References}

[1] S. Verma and A. Gustafsson, "Investigating the Emerging COVID-19 Research Trends in the Field of Business and Management: A Bibliometric Analysis 
Approach,” J. Bus. Res., vol. 118, no. June, pp. 253-261, 2020.

[2] A. Haleem, M. Javaid, R. Vaishya, and S. G. Deshmukh, "Areas of academic research with the impact of COVID-19," Am. J. Emerg. Med., vol. 38, no. March, pp. 1524 $1526,2020$.

[3] A. Adarkar, P. Hyde, M. N. Maxwell, and A. Sridharan, "Leading a consumer bank through the coronavirus pandemic," no. March, 2020.

[4] H. Bapuji, F. G. A. de Bakker, J. A. Brown, C. Higgins, K. Rehbein, and A. Spicer, "Business and Society Research in Times of the Corona Crisis," Bus. Soc., 2020.

[5] M. Beck and D. Tobin, "The 2019/2020 Novel Corona Virus Outbreak: An International Health Management Perspective," Open Public Health J., vol. 13, no. 1, pp. 52-54, 2020.

[6] A. L. Phelan, R. Katz, and L. O. Gostin, "The Novel Coronavirus Originating in Wuhan, China: Challenges for Global Health Governance," JAMA - J. Am. Med. Assoc., vol. 323, no. 8, pp. 709-710, 2020.

[7] S. D. Gupta, "Coronavirus Pandemic: A Serious Threat to Humanity," J. Health Manag., vol. 22, no. 1, pp. 1-2, 2020.

[8] B. Y. M. Butler and K. Rivera, "Seven key actions business can take to mitigate the effects of COVID-19," Strategy+Business, vol. March, pp. 1-6, 2020.

[9] R. Tosepu et al., "Correlation between weather and Covid-19 pandemic in Jakarta, Indonesia," Sci. Total Environ., vol. 725, 2020.

[10] The Indonesian COVID-19 Task Force, "Covid-19 Indonesia Distribution Map," 2020. .

[11] Pricewaterhouse Coopers, "COVID-19 : Considering the potential business impacts for Indonesia," Pricewaterhouse Coopers, 2020. [Online]. Available:

https://www.pwc.com/id/en/covid-19-potential-business-impact-for-indonesia.html. [Accessed: 02-May-2020].

[12] B. J. Clawson, J. Kellar, and S. Larsson, "Learning From COVID-19 to Transform Global Health Systems," 2020.

[13] J. E. Hollander and B. G. Carr, "Responding to Covid-19 - A once-in-a-century pandemic?," N. Engl. J. Med., vol. 382, no. 18, pp. 1679-1681, 2020.

[14] R. Bashshur, C. R. Doarn, J. M. Frenk, J. C. Kvedar, and J. O. Woolliscroft, "Telemedicine and the COVID-19 pandemic, lessons for the future," Telemed. $e$ Health, vol. 26, no. 5, pp. 571-573, 2020.

[15] C. M. Christensen, M. E. Raynor, M. Rory, and R. McDonald, "What is disruptive innovation?," Harv. Bus. Rev., vol. 93, no. 12, pp. 44-53, 2015.

[16] Deloitte, "Forces of change: The future of mobility," Deloitte Insights, pp. 1-14, 2019.

[17] C. Christensen, A. Waldeck, and R. Fogg, "How Disruptive Innovation Can Finally Revolutionalize Healthcare," Innosight Ind. Horizons, pp. 1-28, 2017.

[18] J. Fowkes, C. Fross, G. Gilbert, and A. Harris, "Virtual health : A look at the next frontier of care delivery," McKinsey Insights, no. June, 2020.

[19] R. Sterling and C. LeRouge, "On-demand telemedicine as a disruptive health technology: Qualitative study exploring emerging business models and strategies among early adopter organizations in the United States," J. Med. Internet Res., vol. 21, no. $11,2019$.

[20] A. C. Smith et al., "Telehealth for global emergencies: Implications for coronavirus disease 2019 (COVID-19)," J. Telemed. Telecare, vol. 26, no. 5, pp. 309-313, 2020.

[21] H. Leite, I. R. Hodgkinson, and T. Gruber, "New development: 'Healing at a distance'-telemedicine and COVID-19,” Public Money Manag., 2020. 
[22] D. M. Mann, J. Chen, R. Chunara, P. A. Testa, and O. Nov, "COVID-19 transforms health care through telemedicine: evidence from the field," J. Am. Med. Inform. Assoc., vol. 0, no. 0, pp. 1-4, 2020.

[23] R. Ohannessian, "Telemedicine: Potential applications in epidemic situations," Eur. Res. Telemed., vol. 4, no. 3, pp. 95-98, 2015.

[24] McKinsey \& Company, "Telehealth : A quarter-trillion- dollar post-COVID-19 reality? Telehealth : A quarter-trillion- dollar post-COVID-19 reality ?," 2020.

[25] Konsil Kedokteran Indonesia, "Undang-Undang Nomor," 2020.

[26] Kementrian Kesehatan Indonesia, "Corona virus disease 2019," Peratur. Menteri Kesehat. Republik Indones., vol. Nomor 9, no. Pedoman Pembatasan Sosial Berskala Besar dalam Rangka Percepatan Penanganan Corona Virus Disease 2019 (COVID19), pp. 2-6, 2020. 